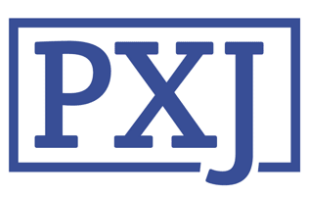

Patient Experience Journal

Volume 6 | Issue 1

Article 18

2019

\title{
Interprofessional collaboration to improve and sustain patient experience outcomes in an ambulatory setting
}

\author{
Natalie Sanchez \\ The University of Texas M.D. Anderson Cancer Center \\ Kimberly Hermis \\ The University of Texas M.D. Anderson Cancer Center
}

Follow this and additional works at: https://pxjournal.org/journal

Part of the Health and Medical Administration Commons, Health Policy Commons, Health Services Administration Commons, and the Health Services Research Commons

\section{Recommended Citation}

Sanchez N, Hermis K. Interprofessional collaboration to improve and sustain patient experience outcomes in an ambulatory setting. Patient Experience Journal. 2019; 6(1):149-153. doi: 10.35680/ 2372-0247.1313.

This Case Study is brought to you for free and open access by Patient Experience Journal. It has been accepted for inclusion in Patient Experience Journal by an authorized editor of Patient Experience Journal. 


\title{
Interprofessional collaboration to improve and sustain patient experience outcomes in an ambulatory setting \\ Natalie Sanchez, The University of Texas M.D. Anderson CancerCenter, nemayo@mdanderson.org \\ Kimberly Hermis, The University of Texas M.D. Anderson Cancer Center, kahermis@mdanderson.org
}

\begin{abstract}
Patient experience is an important factor across diverse healthcare delivery settings. Despite enhanced attention to and advances in patient experience, many of the published initiatives focus on in-hospital care and opportunities have been identified to continue to strategically address patient experience in the ambulatory setting. This quality improvement initiative presents the development of an interprofessional approach to patient experience in a freestanding ambulatory oncology center. The objective of this initiative was to improve and sustain patient experience, as reflected in the Consumer Assessment of Healthcare Providers and Systems (CAHPS) scores via Press Ganey. This approach consisted of redesigning a previously nurse-led patient experience team to include interprofessional providers, including physicians, physical therapists, and administrators. Interventions including specialized training in CAHPS ${ }^{\circledR}$ reports and scoring for both committee members and center staff, quarterly reporting of data to interprofessional teams by service line, and standardization of the communication of best practices to improve patient experience across the center. In addition to outlining the components of the interprofessional initiative, which may be readily translated across diverse care settings, this article demonstrates improved and sustained patient satisfaction data, as measured by 2 years of Consumer Assessment of Healthcare Providers and Systems (CAHPS ${ }^{\circledR}$ ) scores. Findings from this best practice suggest that an interprofessional approach with defined interventions can improve patient experience in the ambulatory setting, resulting in sustained, measurable improvement.
\end{abstract}

\section{Keywords}

Interprofessional collaboration, multidisciplinary, patient experience, ambulatory, CGCAHPS

\section{Introduction}

While patient experience with ambulatory care continues to improve, opportunities exist to further enhance the experience and quality of care. ${ }^{1}$ As attention to patient experience increases in both research and practice initiatives, much of the focus of such work is in the inpatient hospital setting. ${ }^{2}$ Consistent with inpatient findings, a recent study of patient satisfaction and quality outcomes in the ambulatory setting demonstrated that of 8 clinical quality measures only one (mammography screening) was correlated with patient experience. ${ }^{2}$ Despite inconsistent results correlating patient experience with quality outcomes, evidence based recommendations to enhance patient experience during specialty ambulatory encounters include attention to communication between patient and provider, perceived time of engagement with the patient during the encounter, and patient access for appointments and follow-up. ${ }^{3}$ Operational recommendations for ambulatory clinical practices include identifying high priority areas for focus that have the greatest impact on patient experience, reviewing patient satisfaction data at least monthly, and utilizing an interprofessional approach to address deficiencies in patient experience and satisfaction. ${ }^{4}$ This paper will describe best practice and quality improvement initiatives that have impacted patient experience data within one ambulatory center.

Patient experience is influenced by many variables beyond their engagement with medical providers, it is fundamental that approaches to enhancing patient experience be interprofessional in nature. ${ }^{4}$ Such approaches should include attention to care coordination and patient engagement, as well as exploring new care delivery models and their effect on patient experience. ${ }^{5}$ An interprofessional approach, defined as teams with members from two or more health professions, have been identified by patients as supporting patient-centered care and facilitating better communication among care team members in support of the patients' health care delivery. ${ }^{6}$ Interprofessional collaboration is predicated on effective communication, understanding and respecting team member's roles, working together with practical understanding of the clinical context, and recognizing that effective teams require work. ${ }^{7}$ Interprofessional collaboration, including monthly interprofessional team meetings, has demonstrated a positive effect on healthcare

Patient Experience Journal, Volume 6, Issue 1 - 2019

(C) The Author(s), 2019. Published in association with The Beryl Institute and Patient Experience Institute

Downloaded from www.pxjournal.org 
outcomes, ${ }^{8}$ though more recent findings demonstrate inconclusive results. ${ }^{?}$

\section{Institutional Background}

A National Cancer Institute-designated comprehensive cancer center consists of 4 community-based ambulatory centers where patients are seen for treatment and followup. One of these ambulatory centers undertook a revitalization of their Patient Experience Committee in response to an opportunity to improve patient experience scores. This center consists of an ambulatory treatment center, radiation oncology department and 14 medical and surgical clinical service lines with approximately 120 FTEs, including, but not limited to PT/OT, radiation technologists, business personnel, social work, nutrition, and nursing staff. The center served approximately 63,736 patient visits in 2017. This volume has grown by approximately $90 \%$ since 2012 . Transitions to a new electronic health record and the newly released Press Ganey Medical Practice survey offered an opportunity to restructure the Patient Experience Committee and to identify new evidence-based interventions to update practice. This committee was focused on prioritizing patient needs and concerns as evidenced by specific areas within the CGCAHPS ${ }^{\circledR}$ questions. The aim of this process improvement initiative was to enhance communication among interprofessional colleagues at this Center and to identify shared interventions to improve patient experience, as measured by the CGCAHPS ${ }^{\circledR}$ scores. This quality improvement article presents the formation of the new Patient Experience Committee, major initiatives implemented, and outcomes, as well as implication for practice across ambulatory healthcare delivery settings.

\section{Methods}

\section{Outcome Measures}

The Consumer Assessment of Healthcare Providers and Systems $\left(\mathrm{CAHPS}^{\circledR}\right)$ surveys are a standard instrument for measuring the patient experience across health care settings. ${ }^{10}$ The Clinician and Group (CG) $\mathrm{CAHPS}^{\circledR}$ is utilized to measure satisfaction with ambulatory care. ${ }^{11}$ CGCAHPS scores have been used as an outcome measure for patient satisfaction in the clinical setting and have been analyzed in the context of research, with many studies evaluating communication training for providers and interventions for patients to enhance these outcomes. ${ }^{12}$ The CAHPS ${ }^{\circledR}$ surveys also serve as one of the primary measures of assessing communication outcomes in the context of cancer care. ${ }^{13}$ CAHPS $^{\circledR}$ is highly recommended for use in evaluating the efficacy of quality and process improvement initiatives aimed at improving patient experience and satisfaction. ${ }^{10}$

\section{Development of an Interprofessional Patient Experience Committee}

Consistent with recommendations that the success of patient experience initiatives results from top leadership engagement ${ }^{14}$, the development of the Patient Experience Committee was generated by the center's senior leadership. Leaders reached out to each area of the center to ensure that all practice areas were represented on the committee. While participation was voluntary, the leaders purposefully recruited to identify members from nursing, scheduling, radiation therapy, advanced practice providers, new patient registration, physical therapy, physicians and administrators. The committee leadership also engaged with the institutional Patient Family Advisory Council to obtain patient and caregiver feedback on its processes. Recently this has resulted in the identification of a need for a patient committee member who will attend committee meetings and provide feedback and recommendations on initiatives.

Of particular importance, specifically given that many of the CGCAHPS ${ }^{\circledR}$ scores involve assessment of patientprovider engagement, was the inclusion of a physician representative on the committee. Though there was physician support for the committee, historically there was not a dedicated physician committed to attend each meeting. The physician committee member was chosen strategically, first, because she is a recognized advocate for patient experience and quality; and second, out of 17 physicians scores that impact overall center scores, this individual's response rates alone made up $20-25 \%$ of the total center score. The physician liaison's volume, combined with that of her two Medical Oncology peers, made up $65-75 \%$ of the total center score. Engagement of this physician would allow for potential piloting of initiatives in her practice area, which comprises the largest volume of patients seen at this center, and thus reflects the largest volume of CGCAHPS ${ }^{\circledR}$ responses. The physician liaison was also critical to the committee because she was allowed to make decisions related to patient experience in collaboration with the Center Medical Director, allowing for decisions to be made efficiently. The inclusion of the physician as an active member is also consistent with literature suggesting physicians must work together with interprofessional staff to affect patient experience outcomes. ${ }^{6,10}$

Once the team was formed, a first priority was establishing aims for the committee and providing evidence-based education on patient satisfaction to ensure all team members understood the concepts and were committed to the aims of the committee. Education included a focus on the CGCAHPS ${ }^{\circledR}$, how to interpret the scores and percentile rankings, and what each domain of the CGCAHPS $^{\circledR}$ survey reflected in terms of patient satisfaction. This education allowed members of the committee to conduct broader and more in-depth 
discussions of scores with their primary clinical teams and departments.

The committee then reviewed existing CGCAHPS ${ }^{\circledR}$ data for the center. Several quarters of scores were reviewed to evaluate not only a single occurrence, but also trends in patient satisfaction data for this center. The committee then worked to identify potential causes of lower domain scores and engaged in several planning meetings to identify both evidence-based and innovative approaches to improve patient experience. This ideation process not only allowed for the generation of a number of potential interventions, but also for the ownership of these initiatives by diverse stakeholders. Engagement from those at the point of care delivery was imperative to impact the experience of patients within the center. Two primary interventions were then selected, as they were anticipated to have the greatest impact on the CGCAHPS $^{\circledR}$ scores, namely quarterly provider meetings and center wide education.

\section{Initiatives Developed and Implemented by the Committee}

\section{Service-line Based Quarterly CGCAHPS Score Review}

Because the center consists of several service lines it was identified to be potentially beneficial to educate teams of providers, including the physicians, nurses, medical assistants and advanced practice providers, by service line. This allowed for each service line to engage with their CGCAHPS $^{\circledR}$ scores at a more personalized level to identify strengths and opportunities for improvement. In addition, engaging the interprofessional team in these meetings encouraged team-based discussion on how to address scores that were in need of improvement.

The first quarter meeting primarily focused on education about the $\mathrm{CGCAHPS}^{\circledR}$ as it had for the committee members. Many of the providers and team members had rarely engaged with CGCAHPS ${ }^{\circledR}$ scores and needed to understand how to read and evaluate areas for improvement. Education in these processes allowed them to be more knowledgeable about how they compare to their peers. The leadership of the Patient Experience Committee meets with the clinical team to review the scores and comments, and this provides a springboard of individual team ideas to be put into effect. Team meetings have continued to occur over the last 24 months, allowing clinical teams to focus on team-specific opportunities for improvement, as well as identifying and sharing of best practices among various clinic teams.

\section{Center-Wide Information Sharing and Education}

A second opportunity for improvement involved centerwide sharing of best practices. While quality and process improvement initiatives were happening within certain service lines or practice areas, there was not a standardized mechanisms for the broad dissemination of best practices across the center. Several exemplars were and continue to be identified for center-wide implementation and outcomes monitoring. These include the utilization of messaging functionality within our electronic health record to expedite the delivery of test results. Originally utilized by one of the surgical oncology teams and identified during the quarterly provider meeting, this intervention was soon disseminated throughout the center and is believed to have directly impacted the CGCAHPS ${ }^{\circledR}$ item identifying satisfaction with "follows up with test results." When best practices are identified, these are shared via email, during staff and faculty meetings, as well as directly with teams during the quarterly provider meetings.

In addition, center scores are communicated in comparison with institutional scores to provide a pulse on how the center compares to the institution as a whole. This is a driver of staff satisfaction when our scores are leading the institution, and a driver for further improvement if we fall behind. This continued sharing allows for the center to continue to have a line of sight to Patient Experience in between their quarterly team meetings.

The Patient Experience Committee, as well as individual clinical teams, have also implemented a variety of patient centered initiatives. Wait time boards, clinical signage, same day scheduling and lobby rounding are all examples of processes that have been effective in improving the patient experience in coordination with the engagement of the multidisciplinary team.

\section{Outcomes}

The primary outcomes measure of the success of these initiatives was the trending of scores on the CGCAHPS. Specifically, data focused on six domains: Rate provider 010, Recommend this provider office, Physician communication quality, Office staff quality, Care coordination, Access to care 3 months, were tracked and trended. Baseline data was collected from March 2016September 2016. The interventions described above were implemented in September 2016. Trended data are reported in Figure 1. An immediate improvement in scores was noted beginning in first quarter after implementation (FY17 Q1). Yet, while immediate change can often be observed following practice change, more remarkably we have maintained scores above the 90th percentile in all six domain areas. This represents an average improvement of 32 percentiles across each of these areas. 


\section{Discussion}

Consistent with recommendations in the literature, ${ }^{6-8,10}$ an interprofessional team based approach to patient experience that emphasizes communication between both providers and patients, can result in sustainable practice improvements that reflect in patient satisfaction scores. The use of CGCAHPS scores as an impetus for and measure of innovative process improvement ${ }^{10}$ is beneficial to enhancing process and care experience for patients in the ambulatory setting. While studies suggest inconclusive relationships between quality indicators and patient satisfaction both in inpatient and ambulatory settings $8,9,15$, there remains an important emphasis on interventions to enhance patient experience regardless of its influence on quality outcomes. The use of internal marketing, ${ }^{14}$ such as that demonstrated in the center-wide information sharing, can help to promote a shared commitment to priority areas in patient care delivery.

\section{Implications for Practice}

The implementation of a robust Patient Experience Committee allows for center wide improvement. These improvements include education, team engagement, and collaboration as well as improved patient experience. Initiation and long term support of patient experience committees are essential to the overall success for the center, staff and patients. By continuing to study, analyze and implement change based on CGCAHPS ${ }^{\circledR}$ data, best practices begin to emerge. Identifying and sharing these "best practices" allows for standardization of workflows and the beginning of the "culture of always".
Creating an environment among the center that has allowed for transparent discussion about patient experience has demonstrated a sustainable improvement in the patient satisfaction, as evidenced by improved and stable CGCAHPS ${ }^{\circledR}$ scores. Future research and quality improvement opportunities related to best practices directed at patient experience, such as those discussed in this paper, are key to long term success and information sharing among ambulatory settings.

\section{Future Research and Programs}

The aim to improve patient experience is an iterative process involving review of metrics such as CGCAHPS ${ }^{\circledR}$ scores, auditing of processes and workflows, and engagement with patients and providers for their feedback. As such, continued process improvement in this area should focus on providing standardized approaches for reviewing, collaborating on, and sharing of best practices and opportunities for improvement. This paper provides process recommendations to enhance the communication of patient experience data and best practices to enhance that experience across an ambulatory care center. In doing so it supplements literature that is primarily focused on measuring and influencing patient experience in inpatient settings. Further, as patient advisors are increasingly integrated into institutional decision making and process improvement, studies that evaluate how the engagement of patients influences practice change and outcomes may be beneficial in how to optimize this role.

\section{Graph 1. CG-CAHPS Trend by Percentile Rank per Quarter}

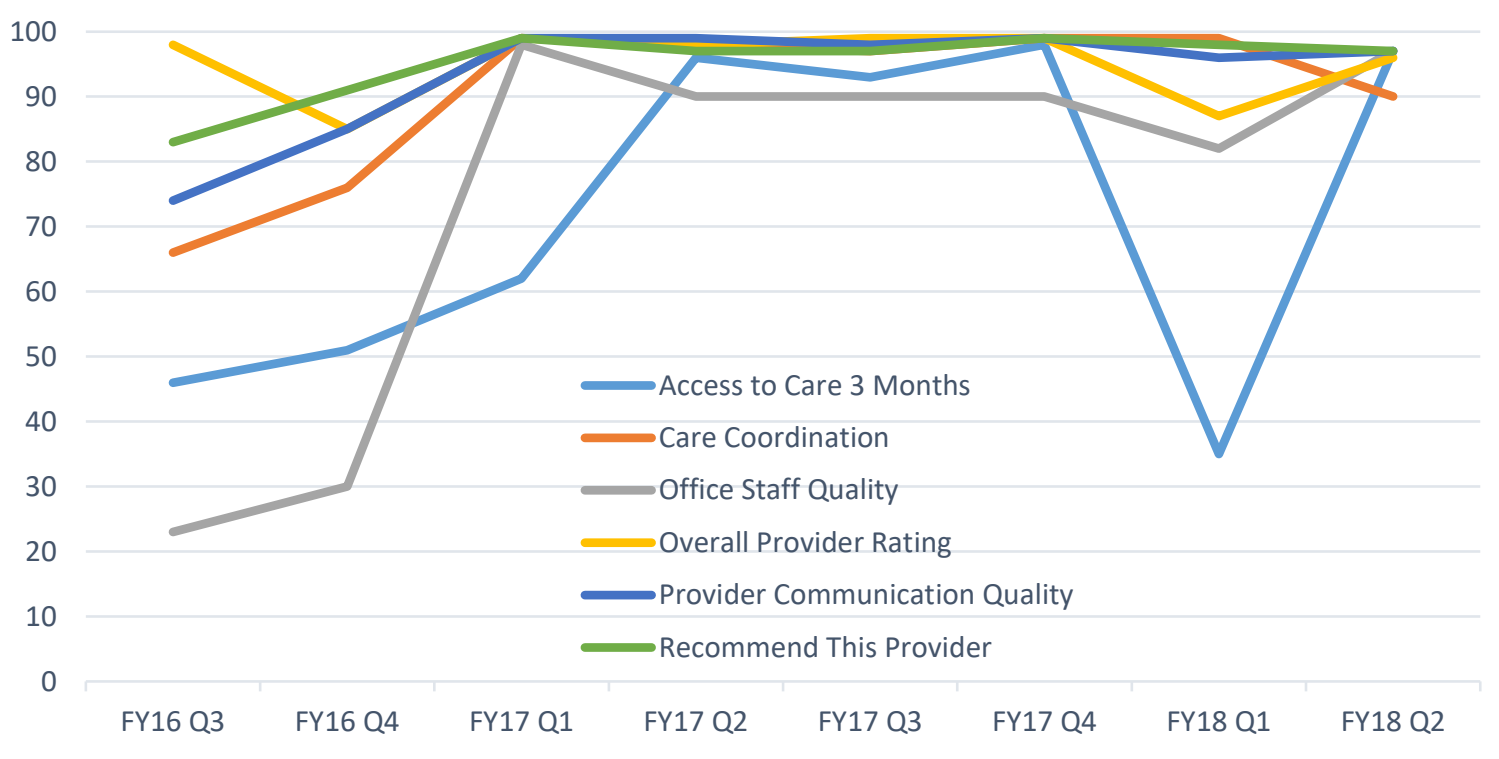




\section{References}

1. Levine DM, Linder JA, Landon BE. The quality of outpatient care delivered to adults in the United States, 2002 to 2013. JAMA internal medicine. 2016;176(12):1778-1790.

2. Congiusta S, Solomon P, Conigliaro J, O'GaraShubinsky R, Kohn N, Nash IS. Clinical Quality and Patient Experience in the Adult Ambulatory Setting. Am J Med Qual. 2018:1062860618777878.

3. Golda N, Beeson S, Kohli N, Merrill B.

Recommendations for improving the patient experience in specialty encounters. J Am Acad Dermatol. 2018;78(4):653-659.

4. Wilson LJ, Yepuri JN, Moses RE. The Advantages and Challenges of Measuring Patient Experience in Outpatient Clinical Practice. Part 4: Acting on Patient Satisfaction Results. Am J Gastroenterol. 2016;111(7):916-917.

5. Manary MP, Boulding W, Staelin R, Glickman SW. The patient experience and health outcomes. New England Journal of Medicine. 2013;368(3):201-203.

6. Shaw SN. More than one dollop of cortex: Patients' experiences of interprofessional care at an urban family health centre. Journal of Interprofessional Care. 2008;22(3):229-237.

7. Sargeant J, Loney E, Murphy G. Effective interprofessional teams: "contact is not enough" to build a team. J Contin Educ Health Prof. 2008;28(4):228234.

8. Zwarenstein M, Goldman J, Reeves S. Interprofessional collaboration: effects of practicebased interventions on professional practice and healthcare outcomes. Cochrane Database Syst Rev. 2009(3):CD000072.

9. Reeves S, Pelone F, Harrison R, Goldman J, Zwarenstein M. Interprofessional collaboration to improve professional practice and healthcare outcomes. Cochrane Database Syst Rev. 2017;6:CD000072.

10. Weinick RM, Quigley DD, Mayer LA, Sellers CD. Use of CAHPS patient experience surveys to assess the impact of health care innovations. Joint Commission journal on quality and patient safety. 2014;40(9):418-427.

11. Morris J, Hotko, B., \& Bates, B. The CG CAHPS

Handbook: A Guide to Improve Patient Experience and Clinical Outcomes. Pensacola, FL: Fire Starter Publishing; 2014.

12. Davidson KW, Shaffer J, Ye S, et al. Interventions to improve hospital patient satisfaction with healthcare providers and systems: a systematic review. BMJ Qual Saf. 2017;26(7):596-606.
13. Street Jr RL, Mazor KM, Arora NK. Assessing patient-centered communication in cancer care: measures for surveillance of communication outcomes. American Society of Clinical Oncology Alexandria, VA; 2016.

14. Fortenberry Jr JL, McGoldrick PJ. Internal marketing: A pathway for healthcare facilities to improve the patient experience. International Journal of Healthcare Management. 2016;9(1):28-33.

15. Bosko T, Wilson K. Assessing the relationship between patient satisfaction and clinical quality in an ambulatory setting. Journal of health organization and management. 2016;30(7):1063-1080. 